\title{
Occurrence of Marek's Disease in Commercial Layer Chicken
}

\author{
R. Ravikumar*, J. Selvaraj, G. A. Balasubramaniam, \\ S. Balakrishnan, T. Lurthu Reetha and R. Thangathurai \\ Department of Veterinary Pathology, Veterinary College and Research Institute, \\ Orathanadu- 614 625, Tamil Nadu, India \\ *Corresponding author
}

\section{Keywords}

Layer chicken, Marek's disease, PCR,

Histopathology

Article Info

Accepted:

22 August 2019

Available Online:

10 September 2019

\section{A B S T R A C T}

Eight dead commercial layer birds of 38 weeks age were examined to know the cause of death. The total flock size was 10,000 and birds were raised in cages from day one of age. The total mortality over a period of 13 weeks was 11.2 per cent. The birds appeared weak and emaciated. At necropsy, liver, spleen, kidney revealed tumour nodules. The tumours were firm in consistency and smooth when cut. Histopathology of liver, spleen and kidney were corroborated the gross lesions. Marek's disease (MD) was confirmed by conducting polymerase chain reaction (PCR).

\section{Introduction}

Marek's Disease (MD) is a highly contagious oncogenic and neuropathic disease of chickens caused by herpes virus and spreads in the environment through feather follicle and infect the birds through inhalation and responsible for great economic losses to the poultry industry world wide (Calnek and Adldinger, 1971). Sporadic outbreaks of MD have been reported recently throughout the world in vaccinated flocks including India (Raja et al.,2009, Gopal et al.,2012). The present paper describes the occurrence of Marek's disease in layer birds raised entirely in cages.

\section{Materials and Methods}

Eight dead commercial layer birds of 38 weeks of age were examined to know the cause of death with a case history of conjunctivitis, off feed, pale comb and 5 per cent loss in production with 11.2 per cent mortality over a period of 13 weeks. The total flock size was 10,000 and all the birds were raised in cages from day one of age. The persistent mortality $(0.70 \%$ per week) was recorded from 26 to 35 weeks of age and it increased at the age of 36 weeks from 0.70 per cent to 1.40 per cent per week. The total mortality over a period of 13 weeks (26 to 38 weeks) was 11.2 per cent. 
A detailed necropsy was conducted on dead birds and gross lesions were recorded. The tissue samples from different portions of liver, spleen, kidney were collected in 10 per cent formalin, processed and sections were stained with haemotoxylin and eosin.

\section{DNA extraction and PCR}

Suspected liver, kidney and spleen samples were collected in dry ice for PCR confirmation (Gong et al., 2013).DNA was extracted by DNeasy blood and tissue kit as per manufacture' instruction. The obtained DNA was stored at $-20^{\circ} \mathrm{C}$ until for further analysis. Then, polymerase chain reaction was carried out by using previously reported primer set forMD as shown in Table 1.

The PCR reactions was carried out in final volume of $25 \mu 1$ which include volume of $12.5 \mu 1$ of master $\operatorname{mix}(2 \mathrm{X}), 1 \mu 1$ of forward and reverse primer each $(10 \mathrm{pmol} / \mu \mathrm{l}), 7.5 \mu \mathrm{l}$ of deionized water and $3 \mu \mathrm{l}$ of extracted DNA and the above mixture of materials was subjected to PCR in a thermal cycler (Eppendorff) as per the procedure of Gong et al., (2013). The analysis of PCR product was carried out in 1.5 per cent agarose gel stained with ethidium bromide $(0.5 \mu \mathrm{g} / \mathrm{ml})$ and documented under Gel documentation system.

\section{Results and Discussion}

\section{Gross pathology}

The affected birds appeared weak and emaciated musculature. At necropsy liver revealed enlarged, greyish white firm tumour nodules from pinpoint to $2 \mathrm{~mm}$ in diameter on the liver parenchyma (Fig.1).

Spleen was enlarged 2- 3 times with diffuse white or greyish military lymphomas scattered all over the surface (Fig.2). Kidneys were enlarged, pale with big whitish nodules on the surface (Fig.3). The gross changes of liver, spleen and kidney observed in this study agreed with the findings of earlier workers (Balachandran et al., 2009, Arulmozhi et al.,2011 and Swathi et al., (2012). The other changes observed were atrophy of bursa of fabricius, proventriculus thickening and congested lungs.

\section{Histopathology}

Histopathology study of Marek's disease suspected liver showed confluent severe pleomorphic lymphoid cell infiltration (PLC) in hepatic parenchyma(Fig.4).

In spleen diffuse moderate PLC with mitotic figures were noticed (Fig.5). In kidney diffuse severe PLC infiltrating the renal parenchyma was noticed (Fig.6).

\section{PCR}

PCR was conducted at Department of Veterinary Microbiology, Veterinary College and Research Institute, Orathanadu- 614625 for 3 samples taken from suspected cases and MDV was confirmed.

Table.1Primer used for detection of MD viruses

\begin{tabular}{|c|c|c|c|c|}
\hline Virus & Primer & Sequence & $\begin{array}{l}\text { Gene and } \\
\text { Size }\end{array}$ & Reference \\
\hline $\mathbf{M I}$ & $\begin{array}{l}\text { Forward } \\
\text { Reverse }\end{array}$ & $\begin{array}{l}\text { F } 5 \text {-GGC ACG GTA CAG GTG TAA AGA G-3 } \\
\text { R } 5 \text {-GCA TAG ACG ATG TGC YGC TGA G-3 }\end{array}$ & Meq,1081bp & $\begin{array}{l}\text { Gong et al., } \\
2013\end{array}$ \\
\hline
\end{tabular}




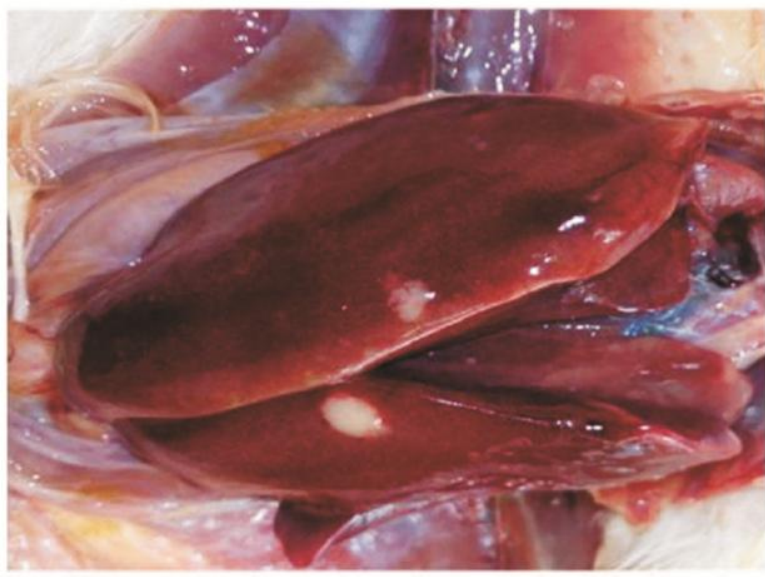

Fig. 1. Chicken -Liver - Enlarged, greyish white firm tumour nodules from pinpoint to $2 \mathrm{~mm}$ in diameter on the liver surface

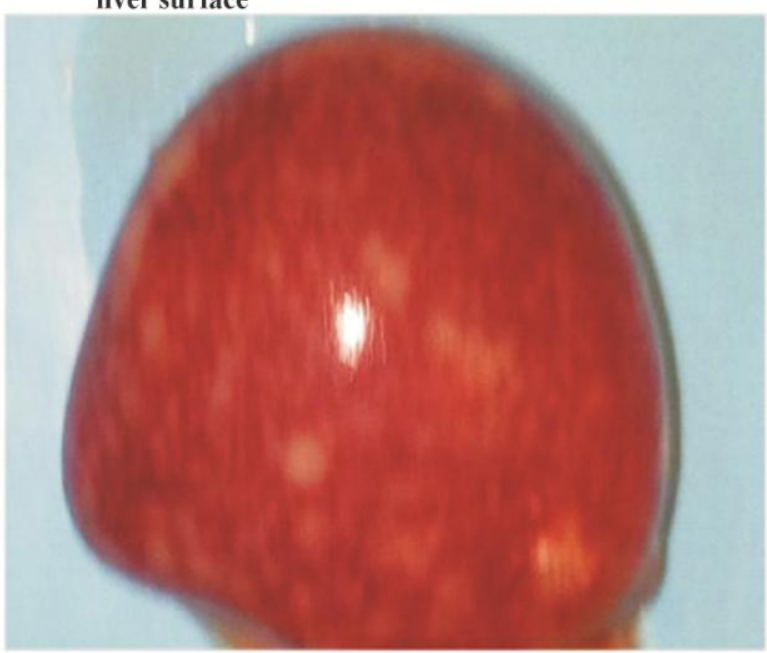

Fig. 2. Chicken - Spleen - Enlarged 2-3 times with diffuse white greyish miliary lymphomas scattered over the surface

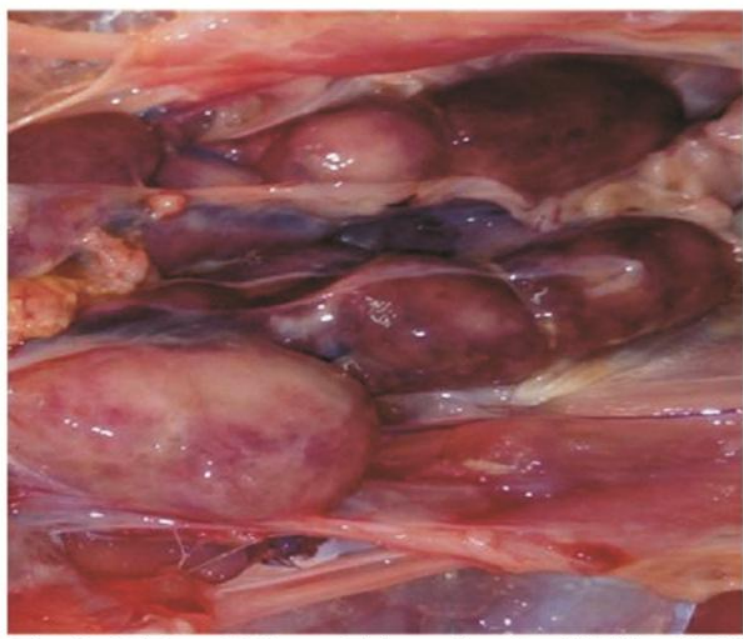

Fig. 3. Chicken -Kidney - Enlarged, pale with big whitish nodules on the surface

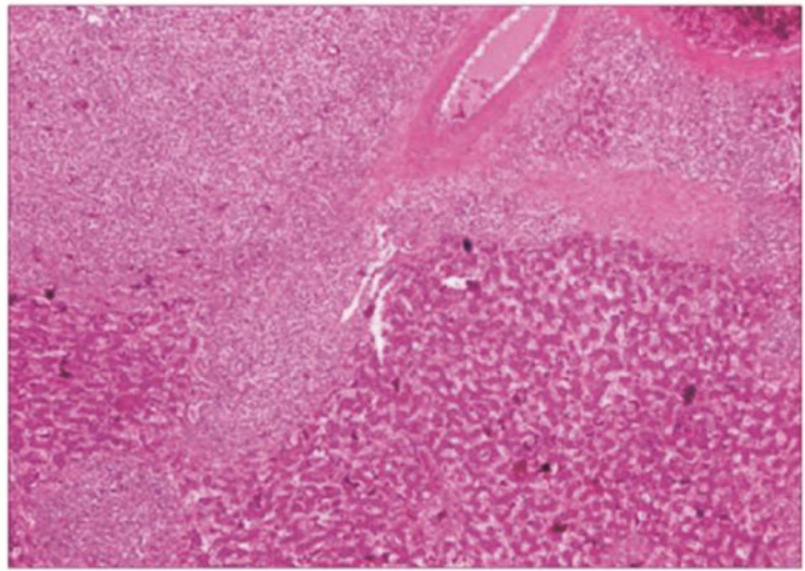

Fig.4 Chicken - Liver - Confluent Severe PLC infiltration in liver parenchyma - $40 \mathrm{X}$

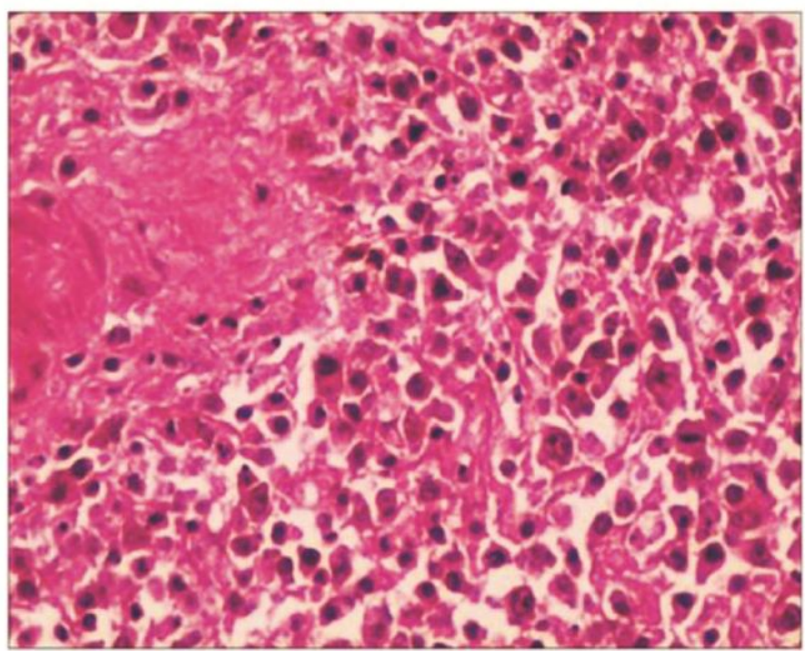

Fig.5 . Chicken - Spleen - Diffuse moderate PLC infiltration with mitotic figures $-400 \mathrm{X}$

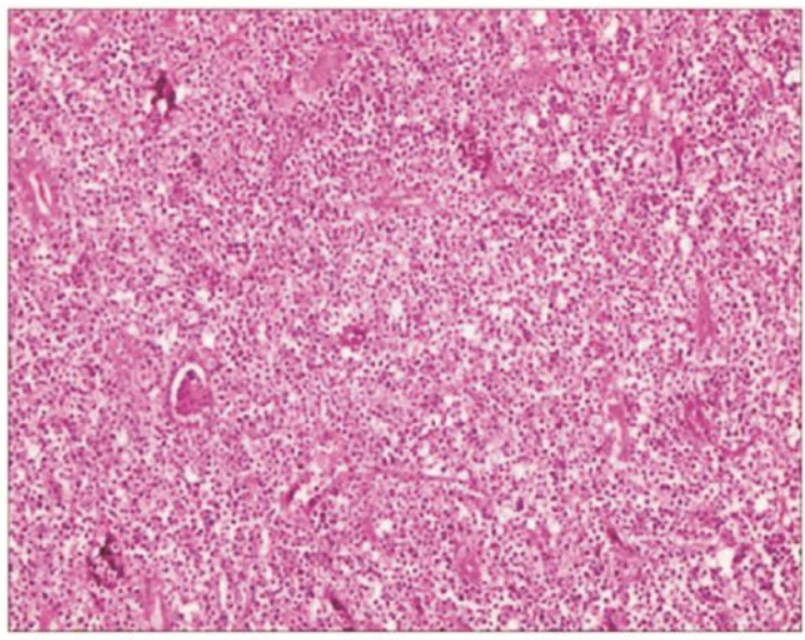

Fig.6 . Chicken -Kidney - Diffuse severe PLC infiltration in kidney parenchyma - $100 \mathrm{X}$ 
Fig.7 M-100 bp ladder, 1(liver), 2 (kidney) and 3 (Spleen) Positive samples with a band at $1081 \mathrm{bp}$ specific for MD , 4- Negative control and 5 - Positive control

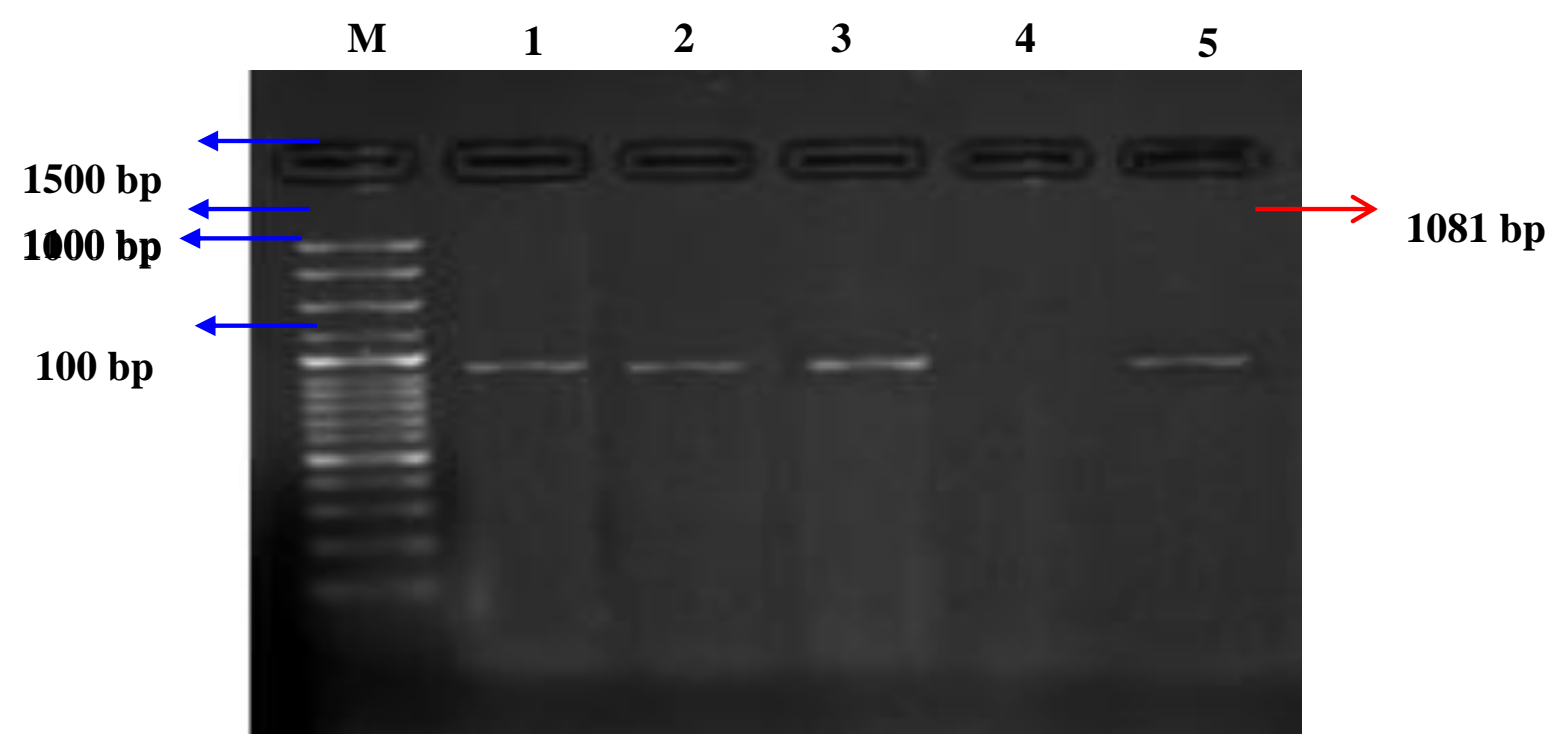

Marek's disease was diagnosed in commercial layer chicken of 38 weeks age. Clinically birds showed 5per cent less egg production, weak, debilitated with 11.2 percent mortality over a period of 13 weeks.

Liver sections revealed confluent severe pleomorphic lymphoid cell infiltration(PLC). Diffuse moderate PLCwith mitotic figures in spleen and kidney revealed diffuse severe PLC. The histopathological changes of liver, spleen and kidney observed in this study agreed with the findings of earlier workers (Balachandran et al., 2009, Mitra et al.,2013 and Bhutia et al., 2017). The PCR test was highly useful for detection of MD virus (Ahmed et al., 2011).

\section{Acknowledgement}

Authors are thankful to the Department of Veterinary Pathology and Department of Veterinary Microbiology, Veterinary College and Research Institute, Orathanadu- 614 625to carry out the part of this work.

\section{References}

Ahmed, H., J. Mays, M. Kiupel and J.R. Dunn.2018. Development of reliable techniques for the differential diagnosis of avian tumour viruses by immunohistochemistry and polymerase chain reaction from formalin fixed paraffin embedded tissue sections. Avian Pathology.,47(4):364-374.

Arulmozhi, A., S. Saravanan, B. Mohan and G.A. Balasubramaniam.2011. Marek's disease in vaccinated poultry flocks in and around Namakkal region of Tamilnadu. Indian J.Vet.Pathol., 35(1): 45-47.

Balachandran, C., N. Pazhanivel, S.Vairamuthu and B.Murali Manohar.2009. Marek's Disease and Lymphoid Leucosis in Chicken-A Histopathological Survey. Tamilnadu J. Vet.Anim.Sci., 5(4): 167-170.

Bhutia,L.D and Y.Damodar Singh. 2017.Marek's disease outbreak in poultry population 
of Mizoram, India. Indian J. Mitra,N., R.Verma and A. Singh.2013. Vet.pathol., 41(3):224-227.

Calnek BW and Adidinger HK.1971.Some characteristics of cell free preparation of Marek's disease virus. Avian Dis., 15:508-517

Gopal,S., P. Manoharan,K. Kathaperumal, K.chidambaram and K.C.Divya.2012. Differential detection of avian oncogenic viruses in poultry layer farms and turkeys by use of multiplex PCR. J.Clin.Microbiol., 50: 2668-2773

Gong, Z., L. Zhang,J.Wang, L. Chen, H.Shan, Z.Wang and H.Ma.2013.Isolation and analysis of a very virulent Marek's disease virus strain in china. Virology Journal, 10: 55-162

Molecular and pathological analysis of oncogenicvirus induced multiple infections in chickens reared under indian conditions. 2013. Nati.Acad.Sci.Lett., 36 (3):271-277.

Raja,A.,G. Dhinakar raj, P. Bhuvaneswari, C. Balachandran and K.Kumanan.2009. Detection of virulent Marek's disease virus in poultry in India. Actavirol.,53: 255-260.

Swathi, B.,A. Anand Kumar and M.R.Reddy.2012. Histological and molecular diagnosis of poultry tumours. Indian J. Vet.pathol., 36: 4148.

\section{How to cite this article:}

Ravikumar, R., J. Selvaraj, G. A. Balasubramaniam, S. Balakrishnan, T. Lurthu Reetha and Thangathurai, R. 2019. Occurrence of Marek's Disease in Commercial Layer Chicken. Int.J.Curr.Microbiol.App.Sci. 8(09): 2422-2426. doi: https://doi.org/10.20546/ijcmas.2019.809.280 